\title{
Cidadania Romana na Epístola aos Filipenses: \\ um diálogo com José Comblin ${ }^{1}$
}

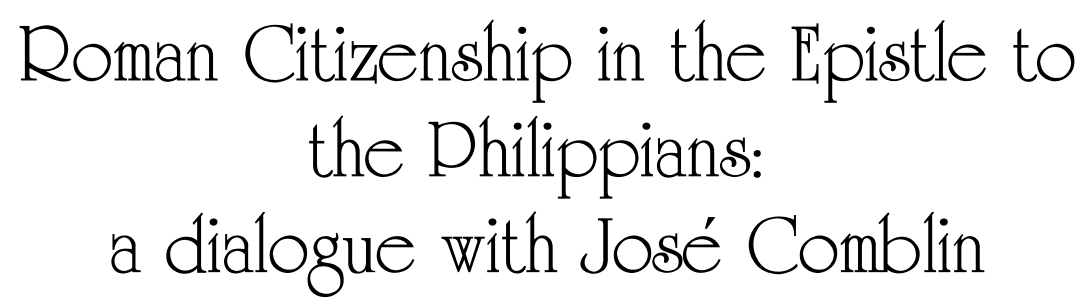

Valter Luiz Lara ${ }^{2}$

Resumo: O presente artigo visa a refletir a interpretação que José Comblin oferece sobre a situação que motivou Paulo de Tarso ao escrever a Epístola aos Filipenses. Trata-se não apenas da retomada do trabalho do mestre Comblin publicado em 1985 como comentário à Epístola, mas de um diálogo que abre novas possibilidade de compreensão do contexto não só de Paulo, mas da própria comunidade a quem ele escreve. O objetivo é demonstrar como o autor entende a prisão de Paulo e o que pode acontecer com ele naquele contexto imediato. Além da possibilidade dessa motivação primeira, cujo centro é a possibilidade do uso da cidadania romana que Paulo, naquele momento, pressupostamente poderia apresentar para "escapar" do martírio, procuramos acrescentar outros elementos do contexto sociológico dos destinatários da carta: a nova vida em Cristo dos filipenses precisa enfrentar as tensões de uma cidade orgulhosa por

\footnotetext{
${ }^{1}$ Artigo que aprofunda e amplia os fundamentos da Comunicação Científica apresentada na I Jornada José Comblin na PUC de São Paulo em 06 de junho de 2019.

${ }^{2}$ Professor de Teologia, Antropologia Teológica e Novo Testamento no UNISAL (PIO XISão Paulo e São José - Campinas) e Membro Pesquisador do Grupo de Pesquisa José Comblin - GPJC, autor do Livro A Bíblia e o Desafio da Interpretação Sociológica, publicado pela Editora Paulus em 2009.
} 
ostentar o status de colônia romana. A situação imediata de Paulo prisioneiro é, sem dúvida, motivação importante de um dos três bilhetes que compõem o conjunto da Epístola. Entretanto, a realidade de conflito social, vivida pela comunidade ao enfrentar o modelo sociocultural de desigualdade dominante, explica o caráter da exortação ética em torno da unidade (Fl 2,1-5) e o modelo cristológico apresentado como critério para viver o exemplo de Jesus que se fez escravo (Fl 2,6-11). Ambos, seguimento de Jesus e o novo modelo de relacionamento humano, são as marcas da identidade cristã que deve prevalecer como testemunho frente aos de fora.

Palavras-chave: Paulo; Filipenses; Comblin; Bíblia; Cidadania Romana.

Abstract: This article aims to reflect Joseph Comblin's interpretation of the situation that motivated Paul of Tarsus in writing the Epistle to the Philippians. This is not only the resumption of Master Comblin's work published in 1985 as a commentary on the Epistle, but a dialogue that opens up new possibilities for understanding the context, not only of Paul, but of the community to which he writes. The goal is to demonstrate how the author understands Paul's arrest and what can happen to him in that immediate context. Besides the possibility of this first motivation, whose center is the possibility of the use of Roman citizenship that Paul, at that moment, might presuppose to "escape" martyrdom, we seek to add other elements of the sociological context of the letter's recipients: the new life in Christ of the Philippians must face the tensions of a city proud to boast the status of Roman colony. The immediate situation of prisoner Paul is undoubtedly an important motivation for one of the three notes that make up the whole of the Epistle. However, the reality of social conflict experienced by the community when facing the socio-cultural model of dominant inequality explains the character of the ethical exhortation around unity (Phil 2: 1-5) and the Christological model presented as a criterion for living the example of Jesus. who became a slave (Phil 2: 6-11). Both following Jesus and the new model of human relationship are the hallmarks of Christian identity that should prevail as a witness to outsiders.

Keywords: Paul; Philippians; Comblin; Bible; Roman Citizenship. 
Valter Luiz Lara

\section{Introdução}

Neste artigo, pretendemos apresentar o privilégio da cidadania romana como tema que subjaz uma das principais razões que levou Paulo a escrever a Epistola aos Filipenses ${ }^{3}$. Na ótica do teólogo Pe. José Comblin, a possibilidade que Paulo tinha de usar sua cidadania romana, para sair da prisão e evitar a morte, necessitava de explicações à comunidade. Sua situação na prisão tornava o martírio uma possibilidade real. Essa é a tese defendida por Comblin ao publicar seu comentário à $F l$ na obra Epístola aos Filipenses (1985).

De nossa parte, além dessa tese de Comblin sobre a motivação de Paulo ao escrever $\mathrm{Fl}$, procuramos acrescentar o cenário tenso e conflitivo que envolvia a própria comunidade destinatária. Nesse cenário, também encontramos motivação suficiente para explicar por que Paulo precisava escrever aos filipenses.

O ponto em comum entre a tese de Comblin e a nossa proposta é a questão da cidadania romana. Comblin reflete a cidadania romana a partir do uso que Paulo pretende fazer dela e, por isso, precisa dar explicações aos filipenses de que não se trata de uma fuga ou medo do martírio. Nossa ótica considera a mesma questão como motivo da carta, não apenas para explicar a situação do remetente (Paulo, prestes a usar o título de cidadão romano para adiar sua morte na prisão), mas para exortar os seus destinatários sobre conflitos que estão vivendo na comunidade. São os conflitos em Filipos que motivam Paulo a escrever. Trata-se de chamar a comunidade à unidade em

\footnotetext{
${ }^{3}$ Nas menções subsequentes, usaremos $F l$ como forma abreviada.
} 
torno do Cristo humilde e escravo e apontar o caminho de superação das tensões típicas de uma sociedade dividida e marcada por desigualdades sociais.

Ao final dos anos 80, nas aulas do Pe. Comblin, mediante o aprendizado com ele e seus escritos, principalmente seu comentário à $F l$, algumas ideias sobre a relação de Paulo com a comunidade de Filipos, no contexto dos problemas sociais vividos por ambos, permitiram o desenvolvimento de uma pesquisa cujo resultado foi a nossa dissertação de mestrado pelo Programa de Ciências da Religião da PUC de São Paulo defendida em 1996 (LARA, 1996). A dissertação, desenvolvida segundo o método de análise sociológica, acabou por revelar em $\mathrm{Fl}$, entre outros temas, a importância de Filipos como colônia de Roma e o impacto que o privilégio da cidadania romana implicava nas relações vividas pela comunidade. Esse artigo quer aprofundar um pouco mais o significado que a cidadania romana tem tanto para Comblin quanto para os nossos estudos de $F l$.

Comblin entendeu a questão da cidadania romana como chave de leitura importante da Carta de Paulo, sempre priorizando, contudo, a situação do remetente (COMBLIN, 1985, p. 11-12; 21), embora reconhecesse que a situação dos destinatários, direta ou indiretamente, também estivessem implicados (COMBLIN, 1990, p. 37). Esses dois enfoques, a do remetente e a dos destinatários, nos inspiraram para a continuidade dos estudos de $\mathrm{Fl}$, numa perspectiva que acrescentava, como aludido acima, o olhar socioanalítico ${ }^{4}$.

\footnotetext{
${ }^{4}$ Mais tarde, depois da publicação do Comentário à $F l$ (1985), Comblin escreveu o artigo "A composição sociológica da comunidade de Filipos" para a Revista Estudos Bíblicos (1990) na mesma perspectiva socioanalítica, cujo conteúdo contribuiu bastante para a minha Dissertação de Mestrado (LARA, 1996).
} 
Valter Luiz Lara

Assim, do diálogo com o mestre, nasceu outra possibilidade de interpretação. Evidentemente que outra chave de compreensão de $F l$ não eliminava a primeira, mas estabelecia exatamente o que, no passado, graças ao trabalho de análise de Comblin e suas provocantes interrogações, constituiu-se como motivação para a descoberta de novas leituras da mesma Epístola.

Desse modo, organizamos o presente trabalho, procurando mostrar essas duas perspectivas complementares de leitura de $F l$, tendo como ponto em comum a noção de cidadania romana. De um lado, a interpretamos na ótica vivida por Paulo e, de outro, na ótica de suas implicações na vida da comunidade. Em primeiro lugar, elaboramos uma síntese das grandes linhas da interpretação do conjunto da Epístola que Comblin escreveu na Introdução ao seu comentário, destacando, desde o início, o tema da cidadania romana como problema relacionado à prisão de Paulo e à legitimação de sua autoridade apostólica (COMBLIN, 1985, p. 7-21); depois, demonstramos outra chave de leitura para o mesmo texto segundo a situação da comunidade; e ao final, como conclusão, apontamos o diálogo possível entre as duas chaves de leitura, destacando obviamente o caráter de complementariedade e de distinção entre elas.

\section{A cidadania romana como chave para entender $\mathrm{Fl}$}

Comblin tem conhecimento das informações mais relevantes sobre o contexto que envolve o envio dos bilhetes de Paulo para a comunidade de Filipos que estão dentro de $F l$. Sabe da importância que a cidade tinha como colônia romana (COMBLIN, 1990, p. 37) na província da Macedônia e 
Revista de Cultura Teológica

Ano XXVII • № Especial I Jornada José Comblin • Out/Nov 2019

reconhece o valor que essa comunidade teve na relação mais próxima e bastante afetuosa com o Apóstolo (COMBLIN, 1985, p. 7-8).

Entretanto, nesse texto, a chave para compreender a mensagem da carta não está centrada na realidade de uma comunidade e os problemas que ela enfrenta na relação direta com a cidade e suas peculiaridades sociopolíticas. O perfil sociológico e os problemas mais diretamente ligados ao contexto militarizado de uma cidade elevada ao status de colônia romana serão mais bem tratados em suas ulteriores publicações (COMBLIN, 1990; 1993). Mesmo assim, embora Comblin considere a temática da cidadania implícita em Fl 3,20: “[...] a nossa cidade está nos céus [...]” (COMBLIN, 1985, p. 55-56), trata-a mais como alusão de Paulo a um dualismo apocalíptico escatológico que opõe o céu à terra do que um questionamento sociopolítico direto ao valor extremo dado à cidadania romana como razão de discriminação de quem não a possui.

Dentro de uma perspectiva apocalíptica, a política propriamente dita fica sem importância. A hostilidade é total entre cristãos e o resto do mundo. O mundo dos inimigos é todo o resto. Não se destacam particularmente as autoridades da cidade de Filipos nem para as autoridades romanas. Tudo desaparecerá na conflagração final (COMBLIN, 1990, p. 39).

No contexto de Fl 3,20, a palavra "cidade" aparece como tradução do termo grego "politeuma". Todavia, em língua portuguesa, não significa exatamente cidade, mas "comunidade de cidadãos", pessoas que pertence à polis grega. Outro termo muito próximo a esse, também presente em $\mathrm{Fl}$ e que possui a mesma raíz, é "politeuesthe" (Fl 1,27). Seu significado literal é viver ou comportar-se como cidadão, mas a Bíblia de Jerusalém (2002) traduz assim:

\footnotetext{
${ }^{5}$ O léxico do Novo Testamento Grego/Português de F. Wilbur GINGRICH (1986, p. 171) define o verbete "politeuma" como "estado", "comunidade", "nação" e acrescenta para o caso específico de Fl 3,20: "talvez com alusão aos veteranos realocados".
} 
Somente vivei vida digna do Evangelho de Cristo, para que eu, indo ver-vos ou estando longe, ouça dizer de vós que estais firmes num só espírito, lutando juntos com uma só alma, pela fé do Evangelho (Fl 1,27) ${ }^{6}$. (grifo nosso)

Comblin, por sua vez, no contexto desse mesmo verso, traduz e interpreta "politeuesthe" de modo mais livre, acentuando o seu caráter comunitário, ao invés de "viver como cidadão":

Por outro lado, levem uma vida comunitária digna do evangelho. Indo vê-los ou ficando longe de vocês, quero ouvir dizer de vocês que estão firmes num só espírito, lutando juntos com uma só alma pela fé do evangelho [F1 1,27] (COMBLIN, 1985, p. 37, grifo nosso)

Aliás, o comentário de Comblin (ibid., p. 37) a propósito desse verso não faz alusão alguma ao conceito de cidadania romana.

Uma vida comunitária digna do evangelho é uma vida fundada na cruz de Cristo, uma vida que não recusa a cruz, a perseguição, o perigo. Ficar firme é resistir à sedução dos falsos evangelhos que não se centram em torno da cruz. Lutar pela fé no evangelho é lutar pelo evangelho da cruz (grifo nosso)

Não há qualquer menção, nesse comentário, à noção de cidadania fundada não mais em ser cidadão romano, mas em ser cidadão do Evangelho (Fl 1,27) e cidadão do céu (Fl 3,20), como bem parece sugerir os termos usados por Paulo. Ao contrário, Comblin lê esse verso na ótica dos "inimigos da cruz de Cristo" (F1 3,18) mencionados por Paulo no contexto de sua alusão aos "falsos circuncidados" (F1 3,2), expressão aplicada aos cristãos judaizantes que exigiam a circuncisão aos membros da comunidade que haviam se

\footnotetext{
${ }^{6}$ A Bíblia de Jerusalém embora traduza "politeuesthe" (imperativo presente, voz média do verbo "politeúomai") como "vivei vida", reconhece, na verdade, o seu significado literal de "vivei como cidadão", uma vez que em nota de rodapé (b) procura esclarecer: "O termo grego significa, em seu sentido primeiro, "levar vida de cidadão", segundo as leis de uma cidade". Ou seja, "politeusthe" deriva da palavra "politeia" que equivale à "civitas" latina, isto é, cidadania para os romanos.
} 
convertido do paganismo (Fl 3). O problema e os adversários da comunidade são, para Comblin, os judaizantes, não os cidadãos romanos. Entretanto, o modo de viver a cidadania (Politeusthe) na comunidade cristã, segundo o Evangelho pregado por Paulo em $F l$, é proposta que se opõe implicitamente ao modo de viver segundo a noção de cidadania romana (Politeuma).

Portanto, o problema em $\mathrm{Fl}$ tem duas faces: uma voltada para os judaizantes (Fl 3,2s) considerados "inimigos da cruz de Cristo" (Fl 3,18); outra voltada para enfrentar os "adversários" (Fl 1,28), identificados implicitamente através da menção de comportamentos que se devem evitar, como o espírito de competição e vanglória, típicos de gente que se considera superior aos demais (Fl 2,2-3), numa provável referência àqueles que ostentam status de superioridade.

Não obstante, Comblin não ignora o papel da cidadania romana como elemento para compreender $F l$, mas o faz na consideração do significado que ela tem na situação do autor mais do que na situação da comunidade para a qual destina sua carta.

\section{Autoridade Apostólica de Paulo questionada}

$\mathrm{Na}$ leitura que Comblin faz de $\mathrm{Fl}^{7}$, o motivo que leva Paulo a escrever aos filipenses é o problema ocasionado por sua própria situação

\footnotetext{
${ }^{7}$ Comblin (1985, p. 8-10) acolhe, como a maioria dos comentadores, a tese de que $F l$ é, na verdade, não uma, mas três cartas: a carta A, mais antiga (F1 4,10-20); a carta $\mathbf{B}$ (F1 1,1-3,1a e 4,2-7.21-23), escrita logo depois da carta A; e a carta $\mathbf{C}$, escrita mediante a polêmica com os judaizantes (Fl 3,1b-4,1 e 4,8-9). A motivação da carta tendo como base o questionamento de sua autoridade como apóstolo envolve as cartas $\mathrm{B}$ e $\mathrm{C}$, mas a situação específica que parece supor a possibilidade de revelar sua cidadania romana refere-se à carta $\mathrm{B}$.
} 
como prisioneiro em alguma cidade do império, provavelmente Éfeso. O problema gira em torno do questionamento que andam fazendo sobre sua autoridade como Apóstolo. Reconhece que a comunidade está dividida em relação a isso e teme que ela seja influenciada por seus adversários que pregam o que ele acredita ser um falso evangelho.

O apóstolo enfrenta um problema de liderança ou de autoridade apostólica. Ele se sente bastante seguro da sua autoridade na comunidade de Filipos. Mas sabe que, apesar da glória da sua prisão, não está seguro da sua autoridade em Éfeso. Pelo contrário, a comunidade está dividida. E, por outro lado, ele soube que os próprios filipenses poderiam ser pertubados por pregadores vindos de outras regiões pregando um evangelho que ele acha falso. Daí o tema da epístola: o problema da autoridade apostólica (COMBLIN, 1985, p. 15, grifo nosso).

Para Paulo, segundo Comblin, o critério fundamental que distingue o verdadeiro do falso evangelho é a cruz de Cristo. Portanto, a autoridade do missionário ou do apóstolo é também identificada pela cruz: "O evangelho que não coloca a cruz no seu centro, não é o evangelho de Jesus Cristo" (COMBLIN, 1985, p. 16).

Comblin vê em $\mathrm{Fl}$ quatro grandes critérios do evangelho da cruz que devem ser aplicados para identificar se um missionário tem de fato autoridade apostólica: $1^{\circ}$ ) só a cruz liberta; ritos, sacrifícios, obras e manifestações de poder não libertam; $2^{\circ}$ ) seguir o esvaziamento de Jesus e ser capaz de renunciar a toda forma de poder; $3^{\circ}$ ) seguir o esvaziamento significa estar disposto a aceitar o martírio; $4^{\circ}$ ) fazer-se escravo das comunidades e servi-lhes. Não viver esses critérios é identificar-se com os “inimigos da cruz de Cristo" (F1 3,18) (COMBLIN, 1985, p. 18-19). 


\section{A cidadania romana de Paulo é problema ou solução?}

Se Paulo defende sua autoridade apostólica alicerçada no princípio do evangelho da cruz, como explicar a possibilidade dele poder escolher viver quando pode aceitar o testemunho do martírio (Fl 1,21-24)? Estaria Paulo fugindo do cumprimento de seu próprio princípio?

O pressuposto, não admitido explicitamente na carta, mas muito provavelmente conhecido por seus interlocutores, era a possibilidade de adiar o veredito da morte, revelando às autoridades sua condição de cidadão romano. ${ }^{8}$ Tal condição lhe daria o direito de escapar ou adiar o martírio, pois lhe permitiria ser julgado em Roma. Mas a escolha por continuar a viver precisava ser esclarecida, uma vez que a comunidade dividida poderia sucumbir aos argumentos daqueles que aproveitariam da circunstância para contestar a autoridade daquele que embora defendesse a cruz, acabava decidindo por fugir dela.

Comblin parece apostar na hipótese da cidadania romana de Paulo como pano de fundo para compreender o dilema relatado em Fl 1,23-24: "23 Sinto-me num dilema: meu desejo é partir e ir estar com Cristo, pois isso me é muito melhor, 24 mas o permanecer na carne é mais necessário por vossa causa".

Se for verdade essa hipótese, Paulo teve oportunidade de escolher $(1,22)$. Escolheu a vida a fim de poder evangelizar de novo. Mas assim fazendo, ele se expôs à crítica de outros evangelizadores. De fato a epístola alude em 1,1518 aos outros missionários, cristãos como Paulo, e verdadeiros pregadores da cruz de Cristo, que aproveitam o pretexto da decisão de Paulo para

\footnotetext{
${ }^{8}$ Paulo se apresenta de fato como cidadão romano apenas em Atos dos Apóstolos $(16,37 ; 22,25)$; em Jerusalém, diante do centurião afirma que a tinha recebido por nascimento (At 22,25-29). No entanto, em suas cartas não há nada a esse respeito. Só aqui em $\mathrm{Fl}$ essa possibilidade parece dar sentido ao que escreve na Carta B, como bem o admitiu Comblin.
} 
desprestigiá-lo: segundo eles Paulo seria um apóstolo fraco porque não teria aceito o martírio, teria fugido da cruz de Cristo (COMBLIN, 1985, p. 12).

O levantamento dessa hipótese explica a razão do dilema (viver ou morrer) e o fato que motivou Paulo a se justificar aos filipenses. Comblin entende que essa situação instigou ainda mais os adversários de Paulo a questionar a legitimidade de seu apostolado. Neste sentido, a Carta B (Fl 1,1-31a + 4,2-7.21-23) foi a oportunidade para apresentar a defesa diante de seus acusadores, esclarecendo o real motivo de sua escolha por continuar vivendo e não ceder à pena capital.

Nenhuma acusação podeia ferir mais o Apóstolo Paulo. Ele era e queria ser precisamente o apóstolo da cruz de Cristo, o missionário radical que não quer saber de outra coisa a não ser de Jesus crucificado. Acusá-lo de rejeitar a cruz na prática da sua vida era a acusação mais dolorosa possível (COMBLIN, 1985, p. 12).

Como vimos, Comblin faz uma leitura de $F l$ centrada na situação de Paulo prisioneiro tomado pela preocupação maior em defender, através de sua autoridade, o evangelho da cruz. Afinal, a decisão de adiar o martírio, parece ter colocado em risco sua credibilidade como apóstolo e, assim, no seu entender, o verdadeiro evangelho, o da cruz de Cristo. Escrever aos filipenses para que permanecessem fiéis ao evangelho, explicando a razão de sua escolha, tornou-se a questão central na defesa que faz contra os seus adversários. O uso que Paulo faz da cidadania romana não é problema, é solução. Porém, o mesmo não ocorre entre os filipenses.

\section{A cidadania romana a partir da comunidade}

Além do foco centrado na situação do autor como parâmetro para leitura de Fl, o contexto sociológico e político de seus destinatários também é 
importante. A situação peculiar que marca a vida comunitária dos filipenses no momento em que Paulo lhes dirige sua carta é componente fundamental para a interpretação de sua mensagem.

As tensões sociais típicas de uma colônia romana dominada pelo orgulho de ser um modelo em miniatura do sistema político da administração imperial eram ainda mais acirradas quando se leva em conta a presença de militares aposentados trazidos por Antonio e Otavio desde a vitória sobre os republicanos (Cassio e Brutus). Trata-se de um contingente que havia servido a Roma e, em Filipos, compunha uma elite consciente de sua condição privilegiada, seja pelos direitos e poderes políticos que tinham como cidadãos romanos, seja pelo acesso à propriedade da terra, além do status de superioridade que ostentavam diante dos outros que não desfrutavam da mesma condição.

Os conflitos e polaridades típicas do sistema romano escravagista e tributário ressoavam nas comunidades cristãs do primeiro século: senhor $\mathrm{x}$ escravo; patrono x cliente; homem x mulher; cidadão romano $\mathrm{x}$ bárbaro estrangeiro.

Nas cartas aos Gálatas e aos Coríntios, além da proposta que fez a Filêmon em relação a Onésimo (Fm 15-16), Paulo não ignorou esse problema. Aliás, não só não ignorou, mas, positivamente, procurou viver e fazer os irmãos de suas comunidades viverem a fé como resposta de relacionamento alternativo, que superasse pelo amor toda forma de discriminação e desigualdade (Gl 3,27-28; 1Co 7). Em Fl, temos esse mesmo Paulo, exortando a comunidade a não ceder à tentação que cada um tem de julgar a si mesmo superior aos outros (Fl 1,3). A cidadania romana não é só uma questão que Paulo precisa justificar, mas é também um problema que 
Valter Luiz Lara

deve suscitar orgulho, privilégios e divisões que a comunidade é convidada a superar (F1 1,27-2,5).

\section{Cidadania do Evangelho fundada no Cristo feito escravo}

$\mathrm{O}$ apelo à unidade é forte e muito presente na Epístola (F1 1,26s; 2,14). A unidade passa pelo reconhecimento do orgulho que se ostenta e que divide. Provavelmente, o desentendimento entre Evódia e Síntique, embora não saibamos os motivos, passe por esse clima de desigualdade, discriminação e orgulho (Fl 4, 2-3).

O hino cristológico (Fl 2,6-11), no centro da carta, testemunha a grandeza da divindade de Jesus, mas só o faz, uma vez traçado o caminho do esvaziamento (do verbo grego Kenów - esvaziar - Fl 2,7a). Ele assume a fragilidade humana e identifica-se com a condição mais vulnerável entre os humanos e se faz escravo (Fl 2,7b).

5 Tende em vós o mesmo sentimento de Cristo Jesus: 6 Ele, estando na forma de Deus não usou de seu direito de ser tratado como um deus, 7 mas se despojou, tomando a forma de escravo, tornando-se semelhante aos homens e reconhecido em seu aspecto como um homem, 8 abaixouse, tornando-se obediente até a morte, e morte sobre uma cruz (F1 2,5-8).

É impressionante a ousadia dessa proclamação de Jesus como escravo. Historicamente, Jesus não era escravo; Timóteo e Paulo (F1 1,1) também não eram, mas todos eles são identificados como tais. Não há como ver, nessa identificação, uma exortação de que a unidade dos filipenses assuma o critério do despojamento e da negação do orgulho de quem se acha superior.

O hino cristológico é um testemunho de que a unidade da comunidade deve assumir o modelo do Cristo, que assumiu a condição do 
humano como escravo e, não, como cidadão romano. Por isso, a honra não está em viver como cidadão romano, mas em viver como cidadão do Evangelho (Fl 1,27). Este é o significado implicado na afirmação de que a cidadania da comunidade está nos céus (Fl 3,20): a cidadania valorosa não é a de Roma, mas a que vem dos céus e que faz o sujeito viver de acordo com os valores do Evangelho.

O ambiente externo era dominado pela lógica do orgulho romano. Não é mera coincidência que Atos dos Apóstolos relate a confusão que Paulo e Silas causaram em Filipos quando libertaram uma escrava da opressão de seus donos, fazendo cessar os lucros deles (At 16,16-24). O texto revela o impacto e a reação dos poderosos diante da nova proposta que o Evangelho de Paulo deveria causar naquele ambiente tipicamente romano:

19 Vendo seus amos que findara a esperança de seus lucros, agarraram Paulo e Silas e os arrastaram à ágora, à presença dos magistrados. 20 Apresentando-o aos estrategos, disseram: "Estes homens perturbam nossa cidade. São Judeus, 21 e propagam costumes que não nos é lícito acolher nem praticar, pois somos romanos" (At 16,19-21). (grifo nosso)

A oposição a Paulo e Silas nesse contexto é claramente romana. O pivô do relato é a libertação da escrava (At 16,16-18) e a negação dos interesses de seus donos (At 16,19), os quais apelam às autoridades civis (magistrados e estrategos) a punição de Paulo e Silas em nome do costume romano (At 16,21). Veja como o problema, nesse relato de Atos, aparece polarizado: escrava x senhores; Paulo e Silas x Senhores e autoridades civis; cidade e romanos x Paulo e Silas.

Como vemos, a comunidade de Filipos enfrentava o desafio da pluralidade segundo o paradigma da desigualdade e discriminação: pessoas de extratos sociais, estatutos jurídicos e etnias diferentes convivem no 
mesmo espaço, mas não necessariamente desfrutam dos mesmos direitos e status social. A experiência nova de amor e comunhão no Espírito (Fl 1,1) precisava de nova legitimação que rompesse com o orgulho predominante da superioridade romana. No caso da comunidades cristã, tratava-se da legitimação religiosa da fé em Cristo. Por isso, $F l$ constrói a lógica de que a cidadania de Cristo só é exaltada (Fl 2,9-11) depois de passar pelo caminho do escravo (Fl 2,7-8).

O hino (Fl 2,6-11) pagão pré-cristão (proveniente do culto de escravos dedicado a um certo Cabirus) adaptado e aplicado a Jesus, senhor e salvador da comunidade, é expressão da legitimação da fé de uma comunidade que deve realizar uma inversão de status, transferindo dignidade, liberdade, valor e poder aos que se encontram na parte debaixo da pirâmide social de uma cidade como Filipos, a saber, imigrantes, pobres, mulheres e escravos.

Portanto, a questão da cidadania romana em $F l$ não está presente só na situação do remetente, mas é problema a ser resolvido também no seio da comunidade.

\section{Conclusão}

O contexto conflituoso sociopolítico bastante peculiar dos destinatários de $F l$ é tão importante para a interpretação de sua mensagem quanto o critério da situação imediata do autor. A decisão de Paulo em escolher continuar vivo para o bem dos filipenses (Fl 1,21-26), ainda que precisasse revelar sua cidadania romana, não tinha nada a ver com a 
ostentação e o orgulho que um tal direito pudesse provocar em cidadãos ou membros da comunidade de Filipos.

Assim como Comblin destacou o tema da cidadania romana como chave de leitura para compreender a justificativa que Paulo tem para dar aos filipenses sobre o uso que dela resolveu fazer em benefício de seu apostolado, é preciso acrescentar que o mesmo tema é objeto de preocupação do apóstolo também no impacto que ele causa na vida da comunidade. A cidadania que vale é a dos céus, a do Evangelho. A outra é mero instrumento para continuar a proclamar o Evangelho de Cristo (Fl 2,27), pois "o viver é Cristo e o morrer é lucro" (Fl 1,21).

\section{Referências}

BÍBLIA. Português. Bíblia de Jerusalém: nova edição, revista e ampliada. São Paulo: Paulus, 2002.

COMBLIN, José. Epistola aos Filipenses. Petrópolis/São Bernardo do Campo/São Leopoldo: Vozes/Imprensa Metodista/Sinodal, 1985. (Comentário Bíblico). Deus Conosco).

. Paulo Apóstolo de Jesus Cristo. Petrópolis: Vozes, 1993. (Coleção . A composição sociológica da comunidade de Filipos. Estudos Bíblicos 25. Petrópolis: Vozes, 1990. p. 34-42.

. Paulo e a cruz de Jesus. RIBLA 20, n. 1. Petrópolis/São Leopoldo: Vozes/Sinodal, 1995.

. Paulo Trabalhador e Apóstolo. n. 11. Belo Horizonte: CEBI, 1988a.

. Paulo e a mensagem de liberdade. Estudos Bíblicos 14. Petrópolis: Vozes, 1987. p. 64-70. 
Valter Luiz Lara

. Atos dos Apóstolos. Vol. II: 13-28. Petrópolis/São Bernardo do Campo/São Leopoldo: Vozes/Imprensa Metodista/Sinodal, $1988 \mathrm{~B}$. (Comentário Bíblico NT).

GINGRICH, F. Wilbur. Léxico do Novo Testamento Grego/Português. São Paulo: Sociedade Religiosa Edições Vida Nova, 1986.

LARA, Valter Luiz. A Epístola aos Filipenses como proposta de relacionamento social alternativo à sociedade de seu tempo. Dissertação de Mestrado. Orientador: José J Queiroz. Programa de Ciências da Religião da PUC de São Paulo, 1996. 